\title{
Kefiran/poly(vinyl alcohol)/poly(vinyl pyrrolidone) composite nanofibers: fabrication, characterization and consideration of effective parameters in electrospinning
}

\author{
Fatemeh Mehrali $^{1} \cdot$ Hakimeh Ziyadi $^{1}$ (D) $\cdot$ Malak Hekmati $^{1} \cdot$ Reza Faridi-Majidi $^{2} \cdot$ Mahnaz Qomi $^{3}$
}

Received: 11 February 2020 / Accepted: 7 April 2020 / Published online: 13 April 2020

(c) Springer Nature Switzerland AG 2020

\begin{abstract}
The kefiran/polyvinyl alcohol and polyvinyl pyrrolidone nanofibers were effectively fabricated for the first time using electrospinning of poly(vinyl alcohol), poly(vinyl pyrrolidone) and kefiran blend solution. The effect of solution parameters, such as kefiran concentration and poly(vinyl alcohol)/poly(vinyl pyrrolidone) mixing ratio, were considered. The parameters' effects, such as voltage, nozzle-to-collector distance and feeding rate on nanofibers morphology, were also checked by the scanning electron microscopy images. After changing the parameters on different steps, designed by the chemo metrics software, the finest nanofibers were produced in the following conditions: $2 \%$ kefiran concentration, 30/70 kefiran/polymer mixing ratio, $12 \mathrm{kV}$ voltage, $200 \mathrm{~mm}$ needle-to-collector distance and $0.5(\mathrm{~mL} / \mathrm{h})$ polymer injection rate. The nanofibers produced in these conditions were uniform without knots or adhesion in the lowest diameter of $156 \mathrm{~nm}$. Kefiran concentration and kefiran/polymer mixing ratio were found as the most effective parameter in the morphology and diameter size of the nanofibers. The attenuated total reflectance (ATR-Ft-IR), atomic force spectroscopy, differential scanning calorimeters and thermal gravimetric analysis were used to investigate molecular structures, threedimensional morphology and heating properties of the nanofibers, respectively.
\end{abstract}

Keywords Poly(vinyl alcohol) $\cdot$ Poly(vinyl pyrrolidone $) \cdot$ Kefiran · Electrospinning · Composite nanofiber

\section{Introduction}

Over the last decade, the electrospinning technique has been developed quickly for the fabrication of nanofibers because it is a simple, versatile, inexpensive and efficient technology for manufacturing sub-micron and industrialscale nanofibers. The broad range of applications for electrospun nanofibers shows their importance, for example in drug delivery [1], wound dressing and tissue scaffolds [2-4], surgical implants [5], composite materials [6], filtration [7], chemical catalysis [8] and electronic devices [9]. Polymeric nanofibers, which have been obtained from the electrospinning method, can produce a large variety of polymers such as commercial, conducting, biological, inorganic, composite, and liquid crystalline polymers [10].

Kefiran (Kf) is an exopolysaccharide from kefir micro flora, which is one of the best edible polymers used in the food industry and packaging material as a texturing and gelling agent [11-13]. It acts against the pathogenic genera Salmonella, Helicobacter, Shigella, Staphylococcus, and Escherichia coli because it has some anti-inflammatory features [14]. Also, it has been reported that kefiran has some antifungal [15], antitumor [16] and anti cholesterolemic [17] characteristics and can modulate the immune

$\triangle$ Hakimeh Ziyadi, behnazziyadi@yahoo.com | 1 Department of Organic Chemistry, Faculty of Pharmaceutical Chemistry, Tehran Medical Science, Islamic Azad University, Tehran, Iran. ${ }^{2}$ Department of Medical Nanotechnology, School of Advanced Technologies in Medicine, Tehran University of Medical Sciences, Tehran, Iran. ${ }^{3}$ Active Pharmaceutical Ingredients Research Center, Tehran Medical Sciences, Islamic Azad University, Tehran, Iran. 
activities [18] and modulate the gut immune system [19]. Kefiran is a water-soluble and branched gluconolactone that is capable of forming an extremely thin film [20] with low opacity and weak mechanical properties; therefore, it needs some modifications for different applications. In order to improve the performance of kefiran, the blending of two or more polymers has been recently suggested [21-24].

One of the processes to get new material with multiplicity properties is the solution blending diverse polymers. These properties are related to the characteristics of the parent polymers and the blend composition [25]. There are many reports about blending of polymers to improve the solubility, chemical and physical properties. To overcome some limitation of poly(vinyl alcohol) (PVA) such as high hydrophilicity, poor stability in water, insufficient elasticity and rigid structure numerous studied reported the blending with poly(vinyl pyrrolidone) (PVP) which led to the preparation of hydrogel or polymers with better properties [26]. PVA have good hetero polymer interaction with PVP due to the sufficient hydrogen bonding between arranged hydroxyl groups along the chain of PVA as a proton-donor with electronegative oxygen and tertiary amides of PVP as a good proton-acceptor [27]. These polymers have been used in fabrication of nanofibers using electrospining method due to their non-toxic, biodegradable and biocompatible properties [10]. Gökmeşe et al. have prepared and characterized PVA/PVP nanofibers as promising materials for wound dressing [28]. Shankhwar et al. have fabricated electrospun PVA/PVP nanofibrous membranes and have approved that mechanical property of the PVA membranes improved significantly with PVP addition. Furthermore PVP improved hydrophilicity and sustainable degradation of the membranes. This study proposed PVA-PVP nanofibrous membranes as promising interactive antibiotic-eluting wound dressing materials [29]. Aytimur and coworkers have investigated that the addition of PVP, to PVA/poly(acrylic acid) (PAA) structure increased the thermal stability of the nanofibers and decrease the fiber diameter [30].

Nano-structures such as nano films and nano composites from PVA and kefiran polymers mixtures have been synthesized [31, 32]. Faridi and his colleagues studied the electrospinning of kefiran nanofibers and effective parameters on its morphology [33]. Their study shows that increasing kefiran concentration up to $4.00 \mathrm{wt} \%$ resulted in the formation of bead-free and uniform fibers. Also, the diameter of kefiran nanofibers increased with enhancing the solution concentrations, the applied voltage and the injection rate. In total it is quite evident that all kefiran nanofibers produced in a variety of conditions in the mentioned study had the diameters over $200 \mathrm{~nm}$. Unfortunately, kefiran alone lacks the necessary stability in thermal and chemical conditions. It is well dissolved in water and is degraded under wet conditions. Moreover, the rheological study of kefiran solutions showed that kefiran solutions did not show important extensional properties, displaying a behavior close to the Newtonian at low Hencky strains [9]. Thus, it seems that because of the importance of kefir as an additive in the food products, the addition of another polymer into the formulation is necessary to achieve higher viscoelastic properties. To improve the physical characteristic of kefiran nanofibers, our research group has studied the effects of PVA addition on kefiran nanofibers in previous research [34]. The results of our study revealed that the produced nanofibers were more resistance than kefiran nanofibers. Nevertheless, the PVA/kefiran nanofibers had higher diameters than kefiran nanofibers. Besides, the diameter of PVA/kefiran nanofibers experienced an increase from 475 to $766 \mathrm{~nm}$ as the proportion of kefiran increased.

Therefore, in this study we decided to use PVA/PVP to be blended with kefiran and considered the effects of PVP addition on the morphology and diameter of kefiran nanofibers. As synthetic polymers, PVA and PVP were used for the preparation of composite nanofibers with kefiran because of their biocompatibility and biodegradability on the one hand and their good electrospinning ability and high mechanical and chemical resistance during the electrospinning process on the other. Using water as a green solvent together with all polymers is another advantage of the composite solution.

Then, after electrospining and characterization with different analyses, the best parameters for the fabrication of nanofibers were determined using SEM images.

\section{Experimental}

\subsection{Kefir grains activation}

Kefir grains were prepared from a home seller. Then, $100 \mathrm{~g}$ of kefir were cultivated in milk for one month to activate the seeds. Each day, the seeds were poured into $800 \mathrm{~mL}$ of low-fat milk in a glass container and then wrapped with foil to prevent light contact at room temperature. After $24 \mathrm{~h}$, the fermented milk of kefir was removed from the seeds. Then, the seeds were washed slowly with water and again cultured in fresh milk. This process continued for one month to activate and increase the volume of seeds.

\subsection{Extraction of kefiran polysaccharide from kefir seeds}

A certain mass of kefir beans was mixed with distilled water in a 1:10 proportion for 40 min using a magnetic 
stirrer. The resulting mixture was poured in a falcon and was centrifuged at $10,000 \mathrm{rpm}$ for $20 \mathrm{~min}$ at $20^{\circ} \mathrm{C}$. The polysaccharide contained in the supernatant (fluid in the falcon after centrifugation) was precipitated by adding $96 \%$ cold ethanol in twice the volume of the supernatant and keeping it for $20 \mathrm{~min}$ in a freezer. After $24 \mathrm{~h}$, the resulting mixture was centrifuged for $20 \mathrm{~min}$ at $4{ }^{\circ} \mathrm{C}$ and dissolved in warm water; the sedimentation process was then carried out twice as described above. The final sediment was placed in an oven at $60^{\circ} \mathrm{C}$ for $48 \mathrm{~h}$ to form kefiran polymer.

\subsection{Preparation of kefiran solution}

As a polymer, $3.62 \mathrm{~g}$ of kefiran were added to the water at $60^{\circ} \mathrm{C}$ for $3 \mathrm{~h}$. Afterward, to completely dissolve the polymer, the temperature was adjusted to $100^{\circ} \mathrm{C}$ in order to prepare a uniform and milky solution. All kefiran solutions with 2, 6 and $10 \%$ wt were prepared by the same method.

\subsection{Preparation of PVA/PVP/kefiran solution}

PVA powder ( $\mathrm{Mw}=88,000 \mathrm{~g} \mathrm{~mol}^{-1}, 88 \%$ hydrolyzed) was purchased from Sigma. Eight grams of PVA powder were dissolved in $100 \mathrm{ml}$ distilled water $(8 \% \mathrm{~W} / \mathrm{W})$ at $60^{\circ} \mathrm{C}$ and were stirred to obtain a homogeneous solution. The PVP (K 90) powder was purchased from Sigma. The PVP solution $(8 \% \mathrm{~W} / \mathrm{W})$ was prepared by the same method at room temperature. The mixture of 50:50 V/V of PVA and PVP were mixed with $\mathrm{Kf}$ solutions (in different concentrations) slowly using magnetic stirrer at $100^{\circ} \mathrm{C}$ for $3 \mathrm{~h}$ in different proportions (70:30, 50:50 and 30:70). Moreover, a 4\% W/W Tween 80 surfactant was added to these mixtures.

\subsection{Electrospinning process}

The main machine used in the fabrication of nanofibers was Electroris (Fanavaran Nano Meghyas Ltd., Co., Tehran, Iran). This device works based on the electrostatic method using a high voltage as a power supply system with an output power of $0-35 \mathrm{kV}$ (DC) and amperage of $0-2 \mathrm{~mA}$ with maximum volatility of $2 \%$. In addition, a syringe pump with a precision of $10 \mu \mathrm{L} / \mathrm{h}$ for injection rate and a cylinder rotary drum in $8 \mathrm{~cm}$ diameter as a collector with a controllable speed up to $3500 \mathrm{rpm}$ were used on this device. A typical syringe $(5 \mathrm{~mL})$ was used to inject a polymer solution and the needle of the 18-gauge type was used as a nozzle. After filling the syringe with a polymer solution, the syringe was placed in its own place and the needle was connected to the high-voltage supply system. To fabricate nanofibers during the electrospinning process, the required high voltage was applied between the nozzle and collector that were coated with aluminum foil. The polymeric solutions were placed in the syringe and then the syringe was placed in its position at the device. The solution was pumped through the needle using the syringe pump. When we adjusted the variable parameters on the device, we saw the state of the exit of the polymer from the nozzle and how to form the Taylor jet when we switched on the voltage. We performed this process for all solutions with different concentrations.

\subsection{Characterization}

Nanofibers obtained from the top of an aluminum foil mounted on a rotating drum were used for further analysis. The coated sheets were cut with scissors in small pieces of $3 \times 3 \mathrm{~mm}$ and the pieces were placed with carbon adhesive on the sample holder. After coating with sputter coater Bal tech (005 SCD), the obtained nanofibers morphology was examined by scanning electron microscopy (SEM, Philips XL30 model).The Fourier transform infrared (FT-IR) spectra of the samples were recorded by Shimadzu $8400 \mathrm{~s}$, Japan. The nanofiber and $\mathrm{KBr}$ pressed mixture were used as a clear disk. All FT-IR spectra were collected in the range of $400-4000 \mathrm{~cm}^{-1}$. The differential scanning calorimeter (DSC) analysis was performed under the nitrogen atmosphere by NETZSCH Differential Scanning Calorimeter. At least $5 \mathrm{mg}$ of each sample was weighed, sealed in aluminum pans, and heated from 25.5 to $350^{\circ} \mathrm{C}$ by a heating rate of $10^{\circ} \mathrm{C} / \mathrm{min}$. The reference material was an empty pan. The area of the melting peak for the sample was calculated by the instrument's software. Atomic force microscopy (AFM) was used for the surface analysis using AFM device NT-MDT Model TD150, Russia. The effects of different parameters on the mean diameter of nanofibers were analyzed by one-way analysis of variance (ANOVA) by the SPSS 16.0 software. The experimental design matrix and data analyses were conducted by the STATGRAPHICS plus 5.1 software. The fiber diameter distribution histogram and average fiber diameters were obtained via SEM image analysis using the Microstructure Measurement and Origin software.

\section{Result and discussion}

\subsection{Electrospinning of Kf/PVA/PVP solution}

Kefiran is an exopolysaccharide produced by microorganisms during the fermentation of kefir grain in milk. This biopolymer has different biological effects that make it highly desirable for food packaging and other application. To improve the physical properties and limitations of this biopolymer, the combination of two biopolymers, such as starch and whey protein, has been used by several researchers $[19,35]$. Herein we used PVA/PVP blend 
polymers for preparation of composite nanofibers with kefiran. According to previous studies, fine and smooth nanofibers of PVA and PVP are gained in $6-10 \%(\mathrm{w} / \mathrm{v})$ and $8 \%(\mathrm{w} / \mathrm{v})$ can produce the thinnest nanofibers possible [36]. PVA and PVP solutions were prepared $8 \%(\mathrm{w} / \mathrm{v})$ in water as solvents. To examine the effects of kefiran concentration on nanofibers' morphology, $2 \%, 6 \%$ and $10 \%(\mathrm{w} / \mathrm{v})$ of kefiran were prepared in water.Tween 80 surfactant was added to these mixtures in order to gain a homogenous solution, to decrease the surface tension of obtained mixtures, to have a continuous electrospinning process and to create fine and smooth fibers.

\subsection{Optimization of electrospinning parameters}

Since several responses were assessed in an experimental design, the optimum points attained individually for each factor did not concur in all cases. There are many statistical methods for resolving multiple response difficulties such as overlaying the contours plot for each response, constrained optimization problems and the desirability approach. However, the most important methodology of the desirability function described is commonly utilized for multi-response optimization. In this study, in order to achieve optimum conditions of electrospinning, a chemo metric design methodology based on a box-Behnken design (BBD) was applied for the optimization of the effective factors on the electrospinning of Kf/PVA/PVP nanofibers.

Several factors were studied in this research: the kefiran concentration and kefiran/polymer ratio as solution effective parameters as well as voltage, nozzle-to-collector distance, and injection rate as device effective parameters on the electrospinning process. All five parameters were changed in three level at their low, mid-range, and high values. The effects of these factors on the morphology, appearance and the diameters of nanofibers were studied by the analysis of the SEM images of the nanofibers. For this purpose, 25 experiments were designed using a chemo metric design. In this design, kefiran concentrations were 2,6 or $10 \mathrm{wt} \%$. The $\mathrm{Kf} /$ polymer ratios were changed in $70 / 30,50 / 50$ or $30 / 70$. Twelve, 18 and $25 \mathrm{kV}$ were selected for the voltage variation. Also, the nozzleto-collector distances ranged from 100, 150 to $200 \mathrm{~mm}$. All the designed experiments were done in conditions shown in Table1.TheSEM images of the experiments are shown in Fig. 1.

\subsection{Effect of parameters on nanofiber diameter}

To achieve the proper concentration of kefiran for electrospinning, different concentrations of kefiran $(2,6$ and $10 \% \mathrm{wt}$ ) were dissolved in deionized water, and then PVP/
PVA solution was prepared at the constant concentration of $8 \%$ in water. As can be seen in Fig. 1, the best morphology of nanofibers was in $2 \%$ wt of kefiran solutions (Fig. 1e, $f, g)$. These images show a smooth, bead less and nanofibrous morphology. In another study, Faridi and his colleagues studied the electrospinning of kefiran alone without any copolymers [33]. They found that $2 \%$ kefiran could not form nanofibers during the electrospinning process. Beadless and uniform fibers were formed by increasing kefiran concentration up to $4.00 \mathrm{wt} \%$ [33]. They used $6 \%$ kefiran as the best concentration to consider the effects of other parameters on kefiran morphology. But in this study, the addition of PVA/PVP to $6 \%$ and $10 \%$ kefiran was not successful in nanofiber fabrication. This phenomenon can be a result of an increase in the viscosity and enhancement of polymer chain entanglement that can decrease the jet path from tip-to-collector distance $[37,38]$.The previous literature also confirms that an increase in concentration can increase the mean diameter of nanofibers $[40,41]$. In the addition of PVA/PVP to $2 \%$ kefiran, the mixing ratio of polymers with kefiran was very important. The fine, beadless and smooth nanofibers were fabricated when the mixing ratio of kefiran with other polymers was 30:70; yet, in kefiran/polymer ratio of $2 \%$ kefiran ( $a, b, c$ and $d)$, a high volume of knots were observed. As observed in Fig. 1, the optimum condition for the electrospinning of Kf/PVA/ PVP was $2 \%$ kefiran with the mixing ratio of $30 / 70$ for Kf/ polymers proportion (see Fig. 1e, f and g).The distributions of fibers' diameters were determined using the measurement software for 20 nanofibers and drawn on the origin software. The distributions histogram of $E, F$ and $G$ are shown in Fig. $2 \mathrm{a}-\mathrm{C}$ ) The mean diameter of $\mathrm{E}, \mathrm{F}$ and $\mathrm{G}$ were 226,173 and 156, respectively. As a result, the optimum voltage, nozzle-to-collector distance and injection rate were $12 \mathrm{kV}, 200 \mathrm{~mm}$ and $0.5 \mathrm{~mL} / \mathrm{h}$, respectively with the diameter of $156 \mathrm{~nm}$ for Kf/PVA/PVP nanofibers. In order to investigate the effects of voltage on morphology, the applied voltage was increased from 12 to $25 \mathrm{kV}$ according to the chemo metric Box-Behnken design as shown in Table 1. Among different voltages, the lowest voltage $(12 \mathrm{kV})$ showed the best result in Fig. 1.G. The literature also confirms that decreasing applied voltage decreases the diameter of nanofibers. The quicker movement of solution from the nozzle to the collector, shorter jet flight time and less time for being stretched in the high applied voltages could lead to thicker and larger nanofiber diameters [42]. When the applied voltage of $6.00 \mathrm{wt} \%$ kefiran solution was raised from 10 to $20 \mathrm{kV}$, the mean nanofiber diameter increased from 193 to $273 \mathrm{~nm}$ [33]. The electrospinning of Kf/PVA/PVP led to thinner nanofibers $(156 \mathrm{~nm})$ than kefiran nanofibers (193 nm) at $10 \mathrm{kV}$.

Nozzle-to-collector distances were changed from 100 to $200 \mathrm{~mm}$ in Table 1 to consider the effects of 
Table 1 Experiments conducted for electrospinning of Kf/PVA/PVP

\begin{tabular}{|c|c|c|c|c|c|}
\hline Experiment & $\begin{array}{l}\text { Kefiran concentra- } \\
\text { tion (wt\%) }\end{array}$ & $\begin{array}{l}\text { Kefiran/poly- } \\
\text { mer ratio\% }\end{array}$ & Voltage & $\begin{array}{l}\text { Nozzell-to-collector } \\
\text { distance }(\mathrm{mm})\end{array}$ & $\begin{array}{l}\text { Injec- } \\
\text { tion rate } \\
(\mathrm{mL} / \mathrm{h})\end{array}$ \\
\hline A & 2.0 & 70.0 & 18.0 & 200.0 & 0.5 \\
\hline B & 2.0 & 70.0 & 12.0 & 200.0 & 2.0 \\
\hline$C$ & 2.0 & 70.0 & 25.0 & 100.0 & 2.0 \\
\hline $\mathrm{D}$ & 2.0 & 50.0 & 18 & 150.0 & 1 \\
\hline$E$ & 2.0 & 30.0 & 25.0 & 100.0 & 2.0 \\
\hline$F$ & 2.0 & 30.0 & 12.0 & 100.0 & 0.5 \\
\hline G & 2.0 & 30.0 & 12.0 & 200.0 & 0.5 \\
\hline $\mathrm{H}$ & 2.0 & 70.0 & 25 & 200.0 & 0.5 \\
\hline I & 6.0 & 50.0 & 25.0 & 150.0 & 1 \\
\hline J & 6.0 & 50.0 & 18 & 100.0 & 1 \\
\hline K & 6.0 & 50.0 & 18 & 150.0 & 1 \\
\hline L & 6.0 & 50.0 & 18 & 150.0 & 2.0 \\
\hline M & 6.0 & 50.0 & 18 & 150.0 & 1 \\
\hline $\mathrm{N}$ & 6.0 & 50.0 & 18 & 200.0 & 1 \\
\hline $\mathrm{O}$ & 6.0 & 50.0 & 12.0 & 150.0 & 1 \\
\hline$P$ & 6.0 & 50.0 & 18 & 150.0 & 0.5 \\
\hline Q & 6.0 & 70.0 & 18 & 150.0 & 1 \\
\hline $\mathrm{R}$ & 6.0 & 30.0 & 18 & 150.0 & 1 \\
\hline$S$ & 10.0 & 70.0 & 25.0 & 100.0 & 0.5 \\
\hline $\mathrm{T}$ & 10.0 & 70.0 & 12.0 & 100.0 & 0.5 \\
\hline U & 10.0 & 70.0 & 12.0 & 200.0 & 2.0 \\
\hline V & 10.0 & 50.0 & 18 & 150.0 & 1 \\
\hline W & 10.0 & 30.0 & 25.0 & 200.0 & 0.5 \\
\hline $\mathrm{X}$ & 10.0 & 30.0 & 25.0 & 200.0 & 2.0 \\
\hline Y & 10.0 & 30.0 & 12.0 & 100.0 & 2.0 \\
\hline
\end{tabular}

nozzle-to-collector distances on the nanofiber diameter. It was observed that the highest distance with $200 \mathrm{~mm}$ resulted in the finest Kf/PVA/PVP nanofibers. The comparison of Fig. If and $g$ shows that changing distance from 100 to $200 \mathrm{~mm}$, other conditions being constant, slightly changed the diameters of nanofibers from $173 \mathrm{~nm}$ to $156 \mathrm{~nm}$. The literature has also pointed out that the effects of nozzle-to-collector distances on nanofiber diameters are not as significant as other parameters [43].The injection rates of polymer from the nozzle were chosen as $0.5,1$ and $2 \mathrm{~mL} / \mathrm{h}$ (Table 1). As can be seen, the optimum condition of Kf/PVA/PVP nanofibers was attained when the injection rate was $0.5 \mathrm{~mL} / \mathrm{h}$. Increasing the injection rate and the high voltage at Fig. 2a (Table 1g) lead to the thickest nanofibers with $226 \mathrm{~nm}$ diameter. These results completely agree with the literature in that an increase in the feeding rate can increase the diameter of nanofibers. Bigger Taylor cone has been produced at the needle in a high injection rate and attained finer nanofibers [44]. However, a very low injection rate could not supply a sufficient amount of solution at the tip of the needle because an excessive increase in the flow rate can result in nanofibers without sufficient solvent evaporation and with flattened, beaded web-like appearance [45]. Therefore, the finest nanofibers are determined by the balance between these two effects. According to our previous study, the finest Kf/PVA nanofibers were fabricated when the 50:50 proportion of Kf:PVA solution was electrospun at the applied voltage and the tip-to-collector distance, injection rate and temperature were selected at $15 \mathrm{kV}$, $150 \mathrm{~mm}, 2 \mathrm{~mL} / \mathrm{h}$ and $35^{\circ} \mathrm{C}$, respectively. The mean diameters of fibers in PVA and Kf/PVA nanofibers were about $254 \mathrm{~nm}$ and $538 \mathrm{~nm}$, respectively, at mentioned electrospinning conditions [34], while the electrospinning of kefiran alone could produce nanofibers with $193 \mathrm{~nm}$ diameters [33]. The blending of PVA and kefiran during the electrospinning process almost doubled the diameter of nanofibers. Therefore, according to the findings, the addition of PVA/PVP to kefiran could decrease the mean diameter of nanofibers $(156 \mathrm{~nm}$ ) in contrast to PVA (254 nm), kefiran (193 nm) and Kf/PVA (538 nm) nanofibers. 

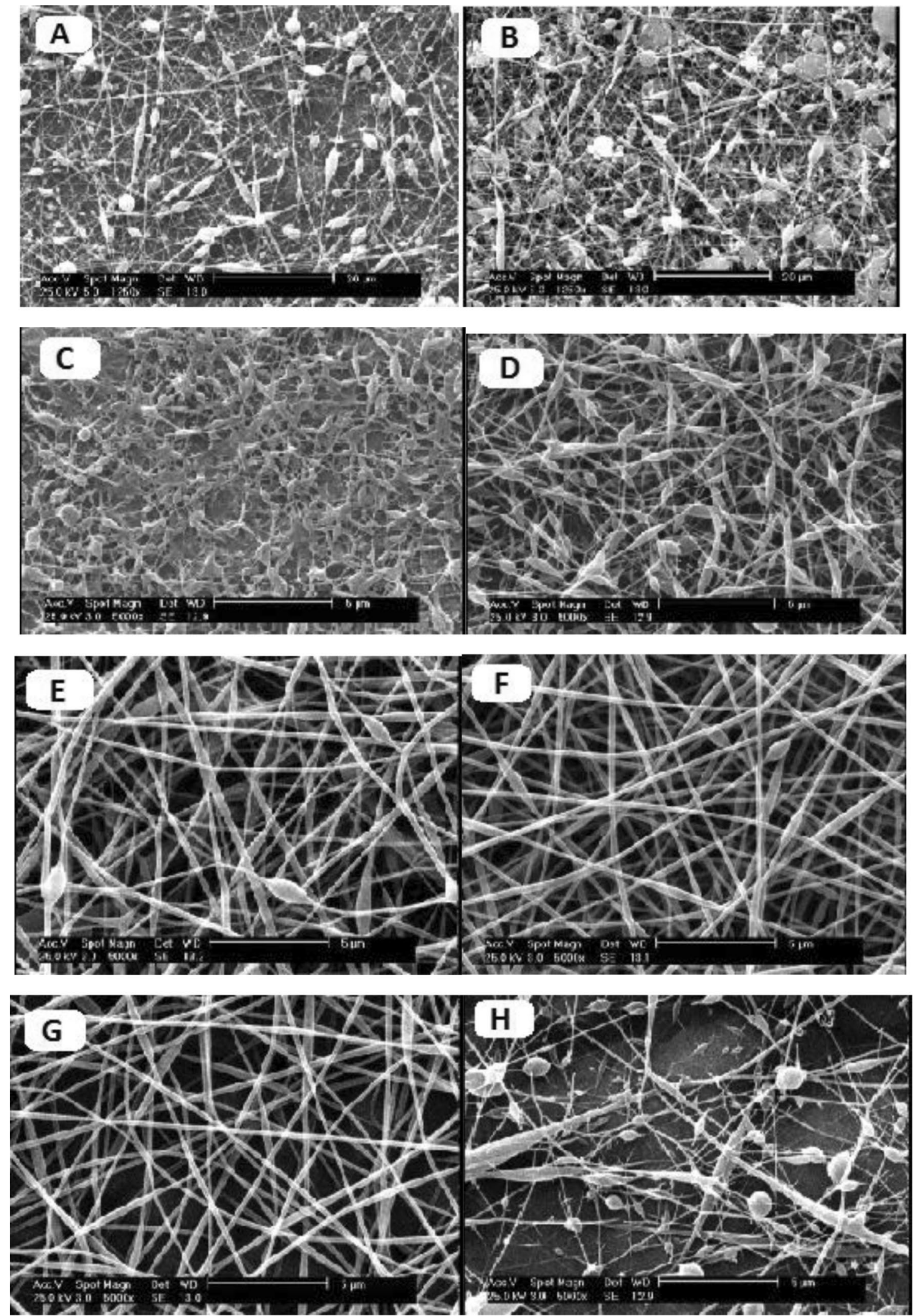

Fig. 1 SEM image of nanofibers

SN Applied Sciences

SPRINGER NATURE journa 

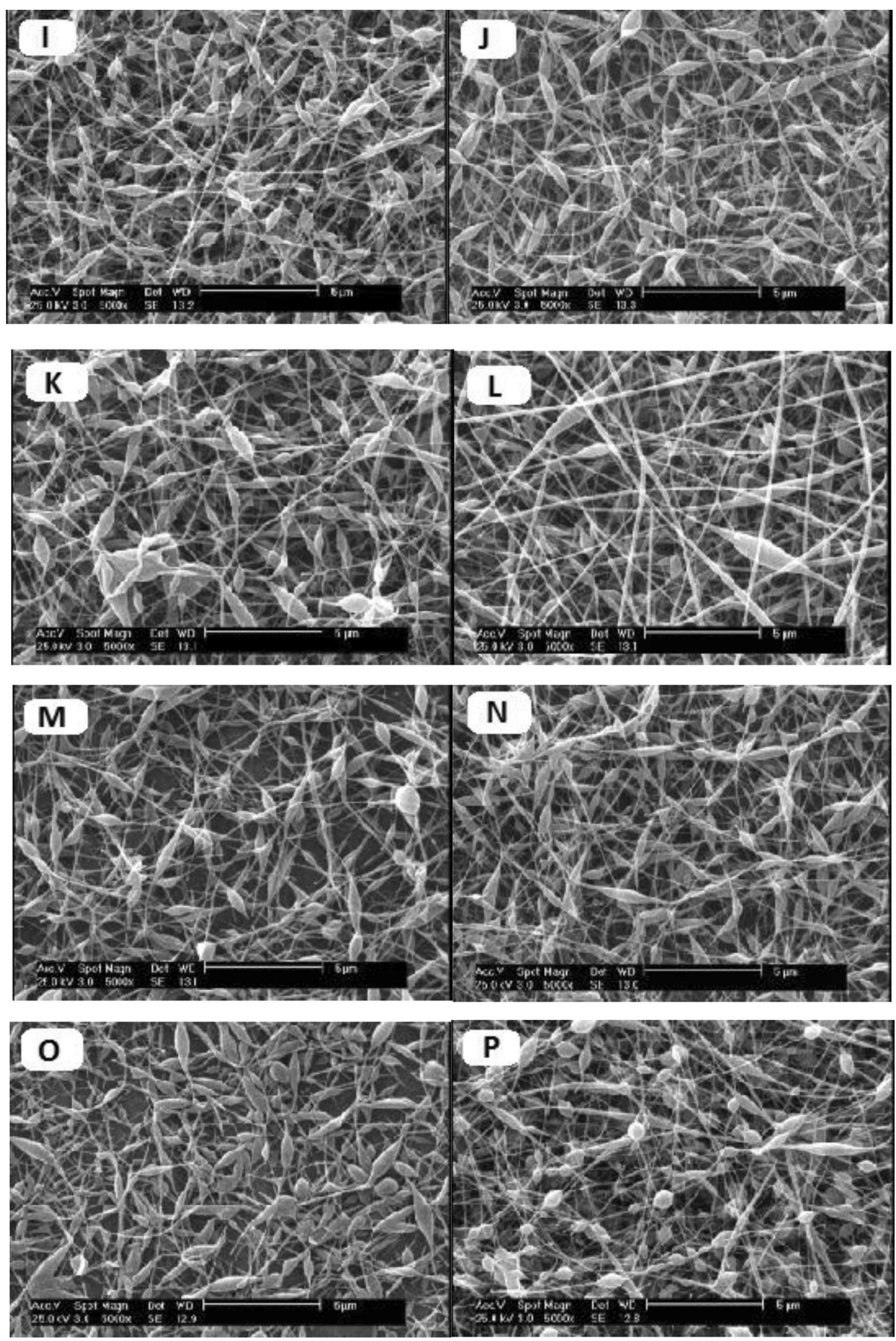

Fig. 1 (continued) 

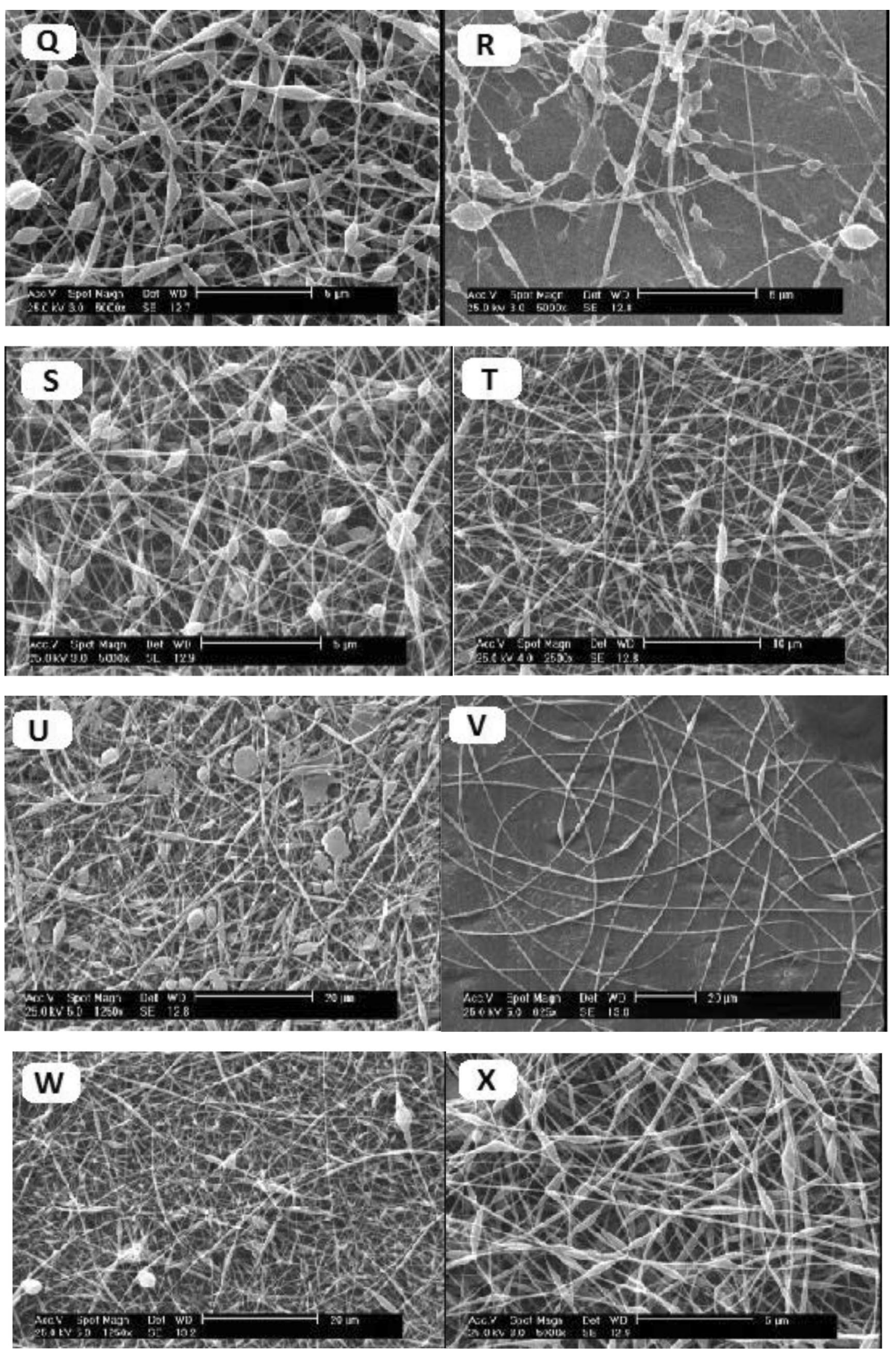

Fig. 1 (continued)

SN Applied Sciences

A SPRINGER NATURE journal 


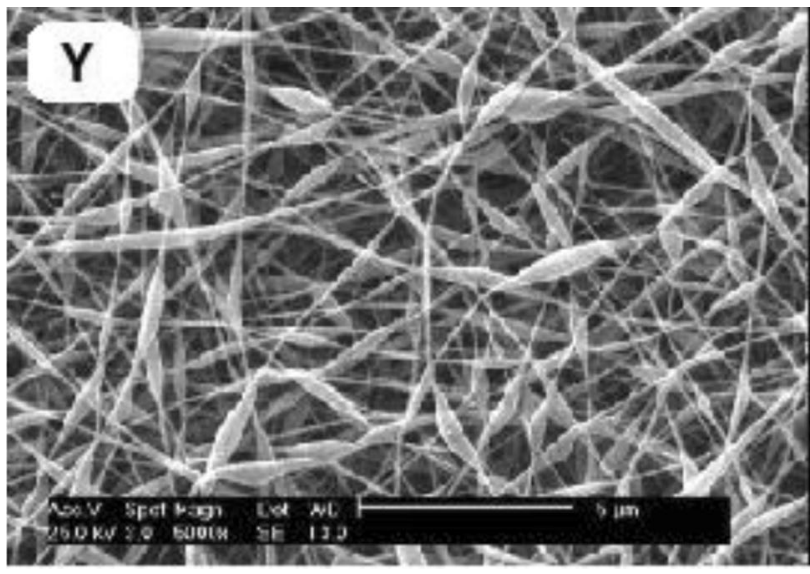

Fig. 1 (continued)

\subsection{Characterization}

After the determination of optimum conditions for electrospinning by the SEM analysis, the characterization of nanofibers was done by FT-IR, DSC and AFM analyses.

FT-IR analysis of PVA nanofiber, kefiran nanofiber, Kf/ PVA nanofiber and Kf/PVA/PVP nanofiber were shown in Fig. 3. The pure PVA nanofibers exhibited various transmittance peaks at $813,1226,1353,1535,1724,2875$ and $3614 \mathrm{~cm}^{-1}$ which were attributed to the $(\mathrm{C}-\mathrm{C}),(\mathrm{C}-\mathrm{O}),(\mathrm{CH})$, $(\mathrm{CH}-\mathrm{OAC})$ and $(\mathrm{C}=\mathrm{O})$ residual from primary vinyl acetate, $(\mathrm{CH} 2)$ and free $(\mathrm{OH})$ resonance, respectively, which is completely agree well with previous studies $[46,47]$. In kefiran nanofiber spectra, peak at $1645 \mathrm{~cm}^{-1}$ are related to bound water [48]. The sharp peak at $1020 \mathrm{~cm}^{-1}$ and finger
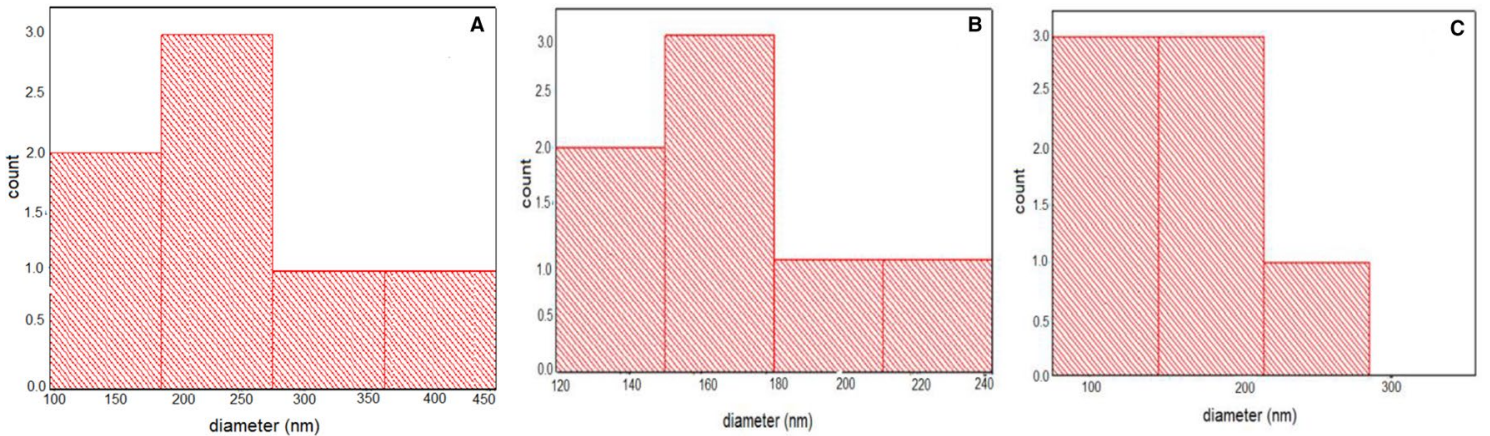

Fig. 2 Diameter distribution of Kf/PVA/PVP with proportion of 30/70 in condition of a sample E with $25 \mathrm{kV}$ voltage and $100 \mathrm{~cm}$ distance $\mathbf{b}$ sample F with $12 \mathrm{kV}$ voltage and $100 \mathrm{~cm}$ distance c sample G with $12 \mathrm{kV}$ voltage and $200 \mathrm{~cm}$ distance

Fig. 3 FT-IR spectra of a PVA, b kefiran, $\mathbf{c}$ Kf/PVA nanofiber, $\mathbf{d}$ Kf/PVA/PVP nanofiber

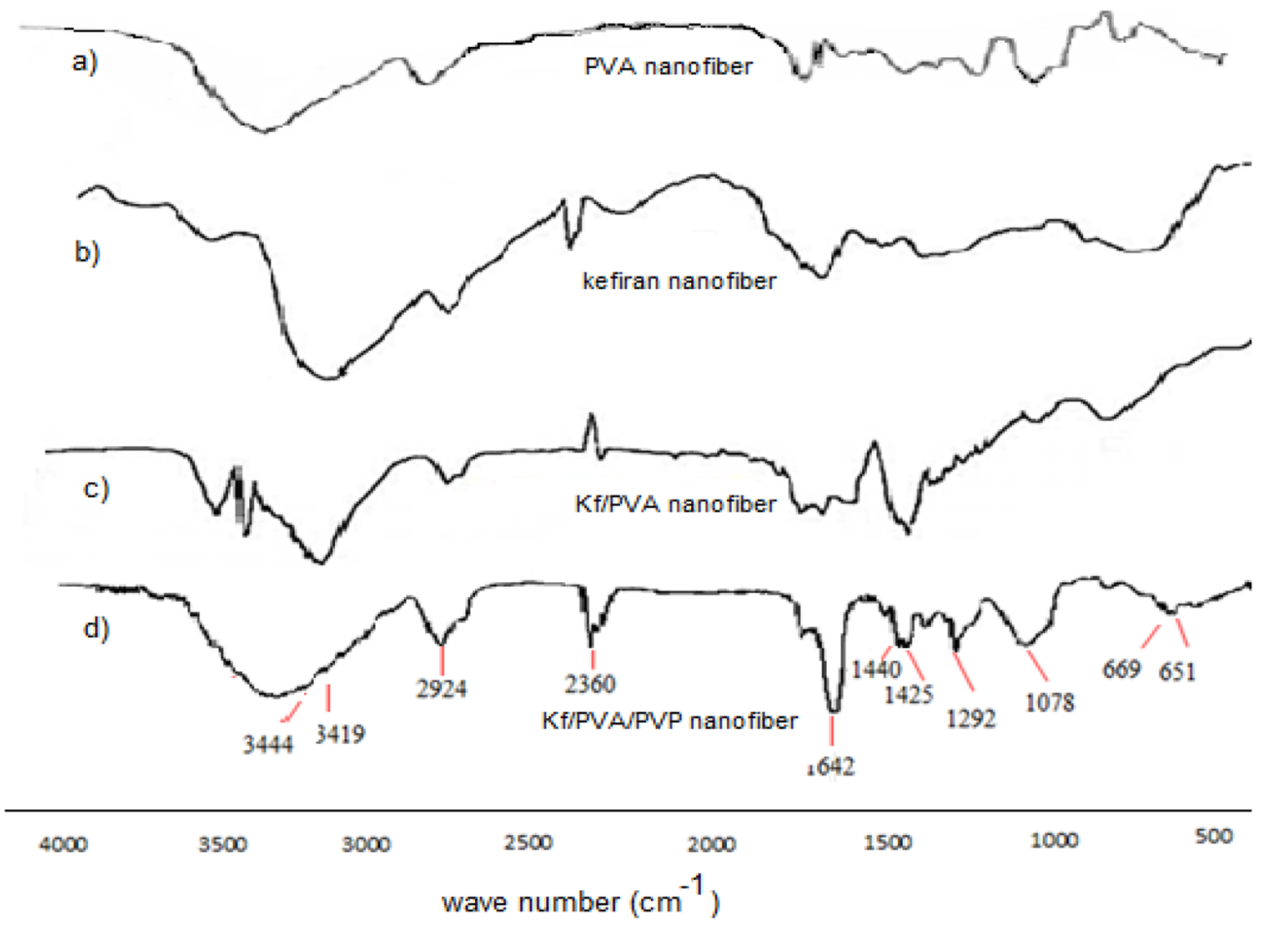

SN Applied Sciences 
print region at $1200-900 \mathrm{~cm}^{-1}$ is characteristic of saccharide structure and stretching modes of carbohydrate [49].The absorption peaks of Kf/PVA nanofibers appear at 2921, 2850,1730,1645, 1440, 1320, 1242, 1095, and $850 \mathrm{~cm}-1$, which were attributed to the $(\mathrm{CH} 2),(\mathrm{CH}),(\mathrm{C}=\mathrm{O})$ residual from primary vinyl acetate, $\mathrm{OH}$ bending, $(\mathrm{CH}-\mathrm{OH})$, $(\mathrm{CH}-\mathrm{OAC}),(\mathrm{CH}),(\mathrm{C}-\mathrm{O})$, and $(\mathrm{C}-\mathrm{C})$ [34]. The absorption bands at 3434, 2955, 1661, 1424,1291 and $1018 \mathrm{~cm}^{-1}$ related to $\mathrm{OH}$ stretching, aliphatic $\mathrm{CH}$, amide $\mathrm{C}=\mathrm{O}, \mathrm{CH}_{2}$ and C-N respectively, are the characteristic peaks of PVP [50].

The FT-IR spectra of Kf/PVA/PVP nanofibers are shown in Fig. 3. d. As shown in the Fig. 3, absorptions peaks appear at $3444,3419,3000,2924,2360,1735,1642,1462,1440$, $1425,1379,1292,1078,669$ and $651 \mathrm{~cm}-1$, which were attributed to the $\mathrm{OH}, \mathrm{CH}$ stretching, $\mathrm{O}-\mathrm{C}=\mathrm{N}, \mathrm{C}=\mathrm{O}, \mathrm{CH} 2$ and $\mathrm{CH}$ vibration, $\mathrm{C}-\mathrm{O}-\mathrm{C}, \mathrm{C}-\mathrm{O}, \mathrm{C}-\mathrm{N}$ and $\mathrm{C}-\mathrm{C}$. The fingerprint region ranged from 900 to $1200 \mathrm{~cm}^{-1}$ is related to the stretching mode of carbohydrate rings and side groups (C-O-C, $\mathrm{C}-\mathrm{OH}$ and $\mathrm{C}-\mathrm{H})$ in $\mathrm{Kf} / \mathrm{PVA} / \mathrm{PVP}$ nanofibers. The broad peaks near 1020, 1095, $1078 \mathrm{~cm}^{-1}$ are characteristic of the saccharide structure in Kf, Kf/PVA and Kf/PVA/ PVP respectively. Furthermore the $\mathrm{C}-\mathrm{N}$ group peak of PVP $\left(1018 \mathrm{~cm}^{-1}\right.$ in PVP) appears as shoulder of $1078 \mathrm{~cm}^{-1}$ peak. The $\mathrm{O}-\mathrm{H}$ bending mode of bound water also resulted in a peak at $1614 \mathrm{~cm}^{-1}$. The appearance of absorption peaks in 2360, 1642 and $1078 \mathrm{~cm}^{-1}$ approved the presence of PVP. These peaks slightly shifted to higher wave number in contrast to pure PVP $\left(2320,1661,1018 \mathrm{~cm}^{-1}\right)$. Likewise, the peaks at $1735 \mathrm{~cm}^{-1}$ and the peaks in the region of $1300-1800 \mathrm{~cm}^{-1}$ corresponded to the bending and stretching vibrations of the PVA. Due to comparison of the previous spectra the hydroxyl group of PVA nanofiber and kefiran nanofiber appear at 3614 and $3000 \mathrm{~cm}^{-1}$, however the Kf/PVA nanofibers shows these two peaks together with. The PVP have a characteristic peaks for $\mathrm{O}-\mathrm{H}$ group of absorbed water at $3434 \mathrm{~cm}^{-1}$ [50]. The appearance of this peak in Kf/PVA/PVP nanofiber led to broad peak at $3000-3600 \mathrm{~cm}^{-1}$ which was indicative of different hydroxyl groups.

Figure 4 shows the DSC thermogram of electrospun Kf/PVA nanofibers and Kf/PVA/PVP nanofibers. It can be seen from the thermogram of Kf/PVA nanofibers that the melting peak appears around $185^{\circ} \mathrm{C}$, but there is no clear melting peak in the thermogram of PVA nanofibers [34]. However, two endothermic peaks were observed in the thermogram of Kf/PVA/PVP nanofibers. These peaks appeared in $276^{\circ} \mathrm{C}$ and $304^{\circ} \mathrm{C}$ with $\Delta \mathrm{H}=-47.6734 \mathrm{~J} / \mathrm{g}$ and $\Delta \mathrm{H}=-43.0745 \mathrm{~J} / \mathrm{g}$, respectively. These peaks appeared in temperatures higher than $205^{\circ} \mathrm{C}$ and $185^{\circ} \mathrm{C}$, attributable to the PVA powder and the melting point of $\mathrm{Kf} /$ PVA nanofibers, respectively. The melting point of PVA increased with the addition of Kf/PVP blend despite the addition of kefiran alone. The degradation temperature of Kf/PVA nanofibers was measured at $266^{\circ} \mathrm{C}$, while the degradation of Kf/PVA/PVP was not observed until $350^{\circ} \mathrm{C}$.

The thermogram analyses showed that the Kf/PVA/ PVP nanofibers were more thermal resistance than Kf/ PVA nanofibers. This may be due to the resistant threedimensional structure of PVP molecules and the good connectivity of blend polymers to each other by a hydrogen bond. Consequently, a strong crystal structure was formed in electrospun Kf/PVA/PVP nanofibers. The higher thermal tolerance of Kf/PVA/PVP composite nanofibers in contrast to kefiran nanofibers and Kf/PVA composite nanofibers makes it a good candidate to be used in many applications such as catalyst, food industry, etc.

The effect of heating on the Kf/PVA/PVP was evaluated by thermal gravimetric analysis (TGA). Figure 5 shows the TGA and DTA curves of the Kf/PVA/PVP nanofibers. The first weight loss at about $100-200^{\circ} \mathrm{C}$ with endothermic peak is
Fig. 4 DSC thermograms of a Kf/PVA nanofiber. b Kf/PVA/ PVP nanofiber

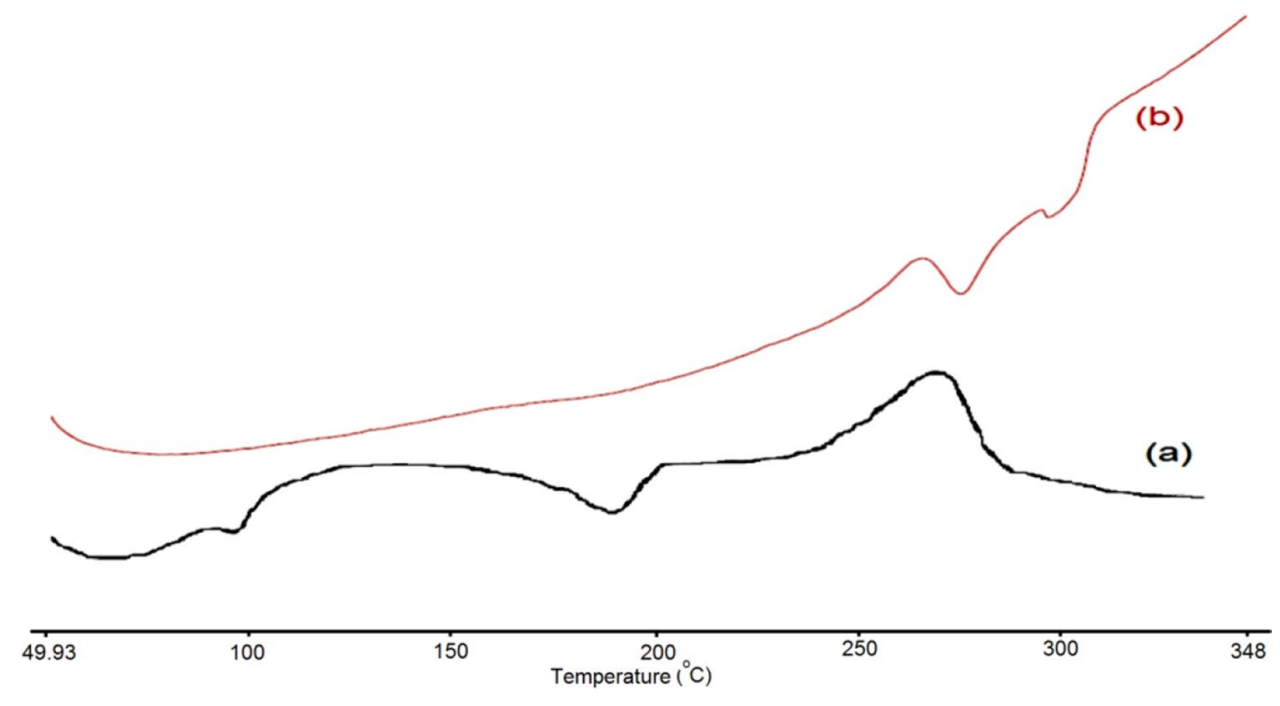




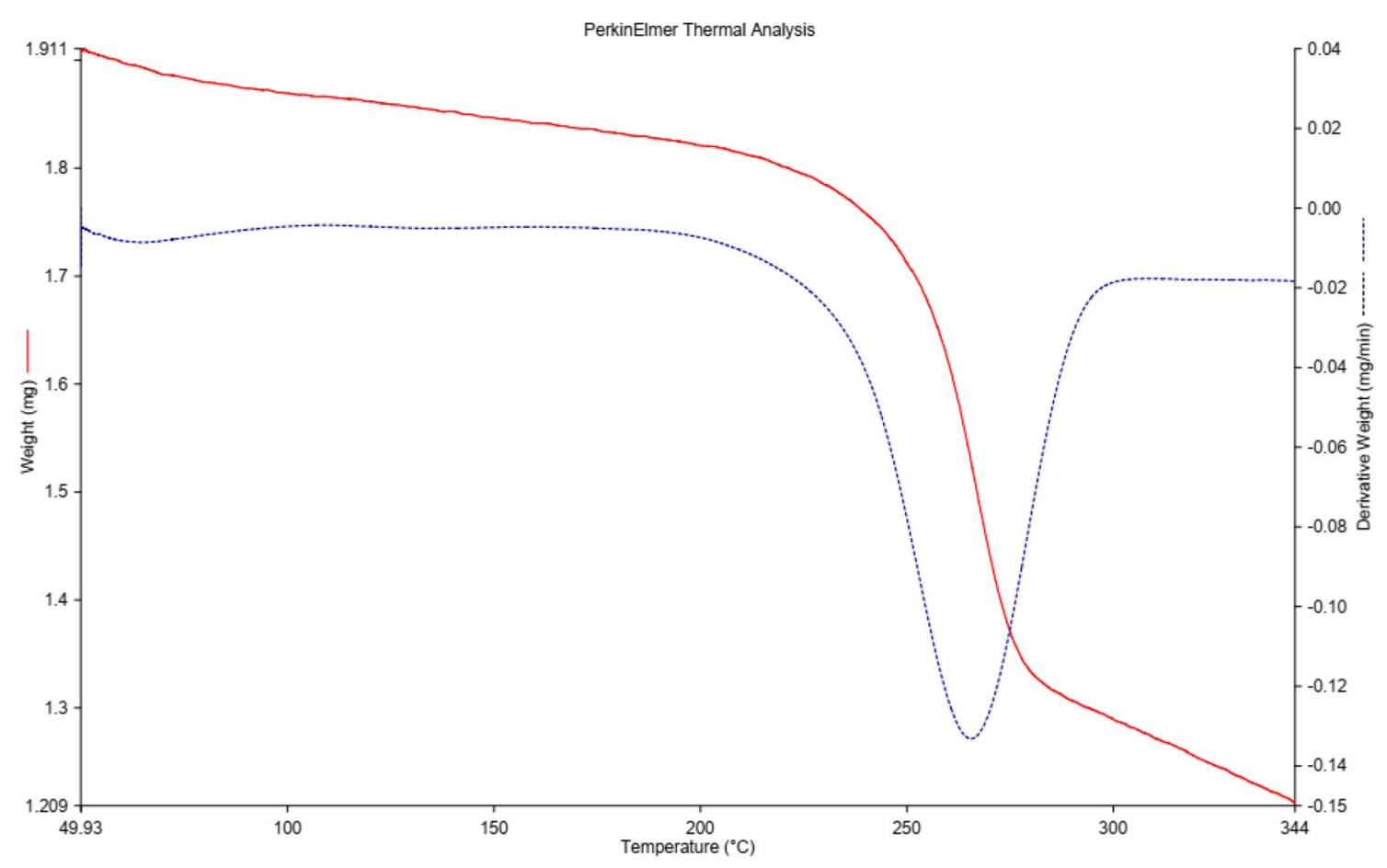

Fig. 5 TGA and DTA analysis of Kf/PVA/PVP nanofibers

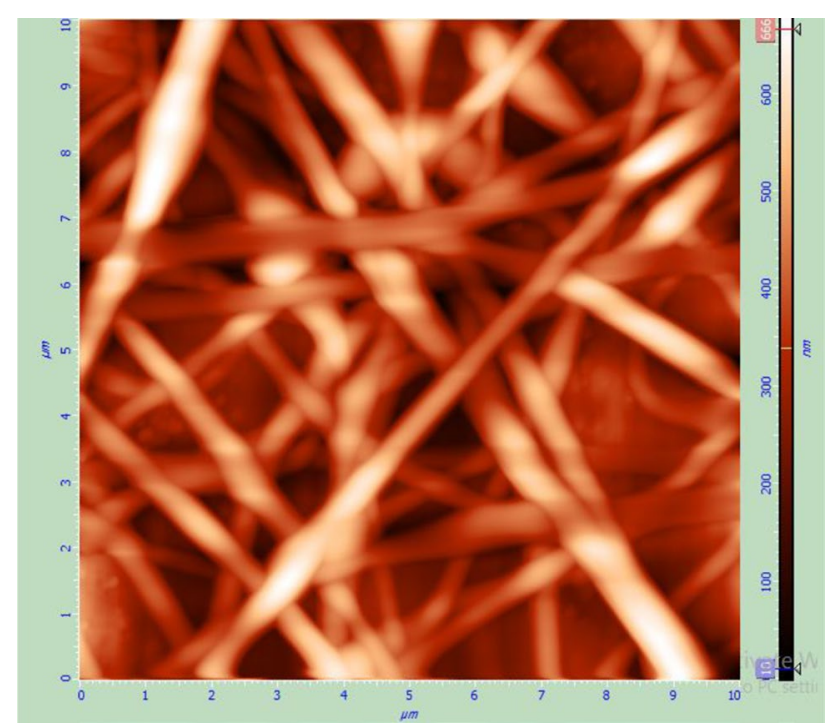

Fig. 6 AFM analysis of Kf/PVA/PVP nanofibers

due to the Loss of adsorbed water. The second and principal weight loss in the range of $250-280^{\circ} \mathrm{C}$ in TGA curve can be attributed to the degradation of PVA and Kf and Kf/ PVA from the nanofiber. The degradation of Kf/PVA/PVP nanofiber was not observed until $350^{\circ} \mathrm{C}$.

The AFM image of Kf/PVA/PVP nanofibers is shown in Fig. 6. In the AFM image, it is possible to capture images from the surface of biodegradable samples with a precision nanometer inline $\mathrm{X}, \mathrm{Y}$ and an angstrom in $Z$-direction approving three-dimensional structure and size. The AFM image can provide information on the properties of material surfaces such as hardness and surface adhesion by measuring the forces between the probe and the sample as a function of their mutual separation in AFM analysis that this method is sometimes referred as atomic force spectroscopy (AFS) [51]. As demonstrated in Fig. 5, the surface topography of nanofibers as a hard material approves the presence of a continuous and smooth nanofibrous structure. It also shows the good porous structure of Kf/PVA/PVP composite nanofibers without adhesion or beads. The high-density fibrous nature of the mats with uniform fibers is in good agreement with the SEM results.

\section{Conclusion}

The aim of this study was the fabrication of Kf/PVA/PVP nanofibers by the electrospinning method. The effects of different parameters such as kefiran/polymer weight ratio, kefiran concentration, voltage, nozzle-to-collector distance, injection on morphology and an average diameter of nanofibers were studied. Results revealed that the most important parameters were $\mathrm{Kf} /$ polymers weight ratio and kefiran concentration. The finest nanofibers were fabricated when $\mathrm{Kf}$ concentration and $\mathrm{Kf} /$ polymers 
weight ratios were $2 \%$ and $30 / 70$, respectively. The reduction of the applied voltage decreased the diameter of nanofibers. The highest nozzle-to-collector distance with $200 \mathrm{~mm}$ could produce the finest Kf/PVA/ PVP nanofibers. Moreover, increasing the feeding rate led to an increase in the diameter of nanofibers. Hence, optimum voltage, nozzle-to-collector distance and injection rate were $12 \mathrm{kV}, 200 \mathrm{~mm}$ and $0.5 \mathrm{~mL} / \mathrm{h}$, respectively, with a diameter of $156 \mathrm{~nm}$ for Kf/PVA/PVP nanofibers. The characterization of nanofibers was done by FT-IR, DSC and AFM analyses. The DSC analysis showed a high thermal tolerance for Kf/PVA/PVP composite nanofibers. The FT-IR analysis agreed well with the molecular structure of PVA, PVP and kefiran. The AFM analysis approved the three-dimensional structure of nanofibers.

Acknowledgements The authors would like to acknowledge the Active Pharmaceutical Ingredients Research Center (APIRC) and the Pharmaceutical Sciences Research Center of Tehran Medical Science, Islamic Azad University, for providing the required equipment and laboratory services.

\section{Compliance with ethical standards}

Conflict of interest We have no conflict of interest.

\section{References}

1. Zong X, Kim KS, Fang D, Ran S, Hsiao BS, Chu B (2002) Structure and process relationship of electrospun bio absorbable nanofiber membranes. Polymer 43:4403-4412

2. Pham QP, Sharma U, Mikos AG (2006) Electrospinning of polymeric nanofibers for tissue engineering applications: a review. Tissue Eng 5:1197-1211

3. Rho KS, Jeong L, Lee G, Seo BM, Park YJ, Hong SD, Roh S, Cho JJ, Park WH, Min BM (2006) Electrospinning of collagen nanofibers: effects on the behavior of normal human keratinocytes and early-stage wound healing. Biomaterials 8:1452-1461

4. Chong EJ, Phan TT, Lim IJ, Zhang YZ, Bay BH, Ramakrishna S, Lim CT (2007) Evaluation of electrospun PCL/gelatin nanofibrous scaffold for wound healing and layered dermal reconstitution. Actabiomaterialia 3:321-330

5. Huang LY, Liu TY, Liu KH, Liu YY, Chao CH, Tung WL, Yang MC (2012) Electrospinning of amphipathic chitosan nanofibers for surgical implants application. J Nanosci Nanotechnol 12:5066-5070

6. Burgshoef MM, Vancso GJ (1999) Transparent nanocomposites with ultrathin, electrospun nylon-4,6 fiber reinforcement. Adv Mater 11:1362-1365

7. Gopal R, Kaur S, Ma Z, Chan C, Ramakrishna S, Matsuura T (2006) Electrospun nanofibrous filtration membrane. J Membr Sci 281:581-586

8. Ghasemi E, Ziyadi $H$, Afshar AM, Sillanpää M (2015) Iron oxide nanofibers: a new magnetic catalyst for azo dyes degradation in aqueous solution. Chem Eng J 264:146-151

9. Nogi M, Iwamoto S, Nakagaito AN, Yano H (2009) Optically transparent nanofiber paper. Adv Mater 16:1595-1598
10. Huang ZM, Zhang YZ, Kotaki M, Ramakrishna S (2003) A review on polymer nanofibers by electrospinning and their applications in nanocomposites. Compos Sci Technol 63:2223-2253

11. Piermaria JA, Pinotti A, Garcia MA, Abraham AG (2009) Films based on kefiran, an exopolysaccharide obtained from kefir grain: development and characterization. Food Hydrocolloids 3:684-690

12. Ghasemlou M, Khodaiyan F, Oromiehie A, Yarmand MS (2011) Development and characterisation of a new biodegradable edible film made from kefiran, an exopolysaccharide obtained from kefir grains. Food Chem 4:1496-1502

13. Shahabi-Ghahfarrokhi I, Babaei-Ghazvini A (2019) Using photo-modification to compatibilize nano- $\mathrm{ZnO}$ in development of starch-kefiran-ZnO green nanocomposite as food packaging material. Int J Biol Macromol 124:922-930

14. Rodrigues KL, Caputo LR, Carvalho JC, Evangelista J, Schneedorf JM (2005) Antimicrobial and healing activity of kefir and kefiran extract. Int J Antimicrob Agents 5:404-408

15. Taniguchi M, Nomura M, Itaya T, Tanaka T (2001) Kefiran production by Lactobacillus kefiran of aciens under the culture conditions established by mimicking the existence and activities of yeast in kefir grains. Food Sci Technol Res 7:333-337

16. Ghasemlou M, Khodaiyan F, Oromiehie A (2011) Physical, mechanical, barrier, and thermal properties of polyol-plasticized biodegradable edible film made from kefiran. Carbohydr Polym 84:477-483

17. Maeda H, Zhu X, Omura K, Suzuki S, Kitamura S (2004) Effects of an exopolysaccharide (kefiran) on lipids, blood pressure, blood glucose, and constipation. BioFactors 14:197-200

18. Medrano M, Racedo SM, Rolny IS, Abraham AG, Pérez PF (2011) Oral administration of kefiran induces changes in the balance of immune cells in a murine model. J Agric Food Chem 59:5299-5304

19. Gagliarini N, Diosma G, Garrote GL, Abraham AG, Piermaria J (2019) Whey protein-kefiran films as driver of probiotics to the gut. LWT 105:321-328

20. Piermaria J, Diosma G, Aquino C, Garrote G, Abraham A (2015) Edible kefiran films as vehicle for probiotic microorganisms. Innov Food Sci Emerg Technol 32:193-199

21. Sabaghi M, Maghsoudlou Y, Habibi P (2015) Novel kefiranpolyvinyl alcohol composite film: Physical, mechanical and rheological properties. Nutr Food Sci Res 2:39-46

22. Shahabi-Ghahfarrokhi I, Khodaiyan F, Mousavi M, Yousefi H (2015) Green bionanocomposite based on kefiran and cellulose nanocrystals produced from beer industrial residues. Int J Biol Macromol 77:85-91

23. Motedayen AA, Khodaiyan F, Salehi EA (2013) Development and characterisation of composite films made of kefiran and starch. Food Chem 136:1231-1238

24. Sabaghi M, Maghsoudlou Y, Habibi P (2015) Enhancing structural properties and antioxidant activity of kefiran films by chitosan addition. Food Struct 5:66-71

25. Ziyadi $\mathrm{H}$, Heydari A (2014) PVA/Fe $\left(\mathrm{NO}_{3}\right)_{3}$ nanofiber mats: an efficient, heterogeneous and recyclable catalyst for the synthesis of quinolines via Friedländer annulations. RSC Adv 4:58208-58213

26. Teodorescu M, Bercea M, Morariu S (2019) Biomaterials of PVA and PVP in medical and pharmaceutical applications: perspectives and challenges. Biotechnol Adv 37:190-131

27. Eisa WH, Abdel-Moneam YK, Shabaka AA, Hosam AEM (2012) In situ approach induced growth of highly mono dispersed $\mathrm{Ag}$ nanoparticle within free standing PVA/PVP films. Spectrochim Acta A 95:341-346

28. Gökmeşe F, Uslu I, Aytimur A (2013) Preparation and characterization of PVA/PVP nanofibers as promising materials for wound dressing. Polym Plast Technol Eng 52:1259-1265 
29. Shankhwar N, Kumar M, Mandal BB, Robi PS, Srinivasan A (2016) Electrospun poly vinyl alcohol-polyvinyl pyrrolidone nanofibrous membrane for interactive wound dressing application. J Biomater Sci Polym Ed 27:247-262

30. Aytimur A, Uslu I (2014) Promising materials for wound dressing: PVA/PAA/PVP electrospun nanofibers. Polym Plast Technol Eng 53:655-660

31. Exarhopoulos S, Raphaelides SN, Kontominas MG (2018) Conformational studies and molecular characterization of the polysaccharide kefiran. Food Hydrocolloids 77:347-356

32. Shahabi-Ghahfarrokhi I, Khodaiyan F, Mousavi M, Yousefi H (2015) Green bio nanocomposite based on kefiran and cellulose nanocrystals produced from beer industrial residues. Int J Biol Macromol 77:85-91

33. Esnaashari SS, Rezaei S, Mirzaei E, Afshari H, Rezayat SM, FaridiMajidi R (2014) Preparation and characterization of kefiran electrospun nanofibers. Int J Biol Macromol 70:50-56

34. BagherianZiyadi MH (2016) Fabrication of polyvinyl alcohol/ kefiran nanofibers membrane using electrospinning. J Pharm Health Sci 4:211-218

35. Babaei-Ghazvini A, Shahabi-Ghahfarrokhi I, Goudarzi V (2018) Preparation of UV-protective starch/kefiran/ZnO nanocomposite as a packaging film: characterization. Food Pack Shelf Life 16:103-111

36. Zhang C, Yuan X, Wu L, Han Y, Sheng J (2005) Study on morphology of electrospun poly(vinyl alcohol) mats. Eur Polymer J 41:423-432

37. Fong H, Chun I, Reneker D (1999) Beaded nanofibers formed during electrospinning. Polymer 40:4585-4592

38. Stijnman AC, Bodnar I, Hans Tromp R (2011) Electrospinning of food-grade polysaccharides. Food Hydrocolloid 25:1393-1398

39. Jia YT, Gong J, Gu XH, Kim HY, Dong J, Shen XY (2007) Fabrication and characterization of poly(vinyl alcohol)/chitosan blend nanofibers produced by electrospinning method. Carbohydr Polym 67:403-409

40. Geng X, Kwon OH, Jang J (2005) Electrospinning of chitosan dissolved in concentrated acetic acid solution. Biomaterials 26:5427-5432

41. Jarusuwannapoom T, Hongrojjanawiwat W, Jitjaicham S, Wannatong L, Nithitanakul M, Pattamaprom C, Koombhongse $P_{,}$ Rangkupan R, Supaphol P (2005) Effect of solvents on electrospinnability of polystyrene solutions and morphological appearance of resulting electrospun polystyrene fibers. Eur Polym J 41:409-421
42. Mirzaei E, Amani A, Sarkar S, Saber R, Mohammadyani D, FaridiMajidi R (2012) Artificial neural networks modeling of electrospinning of polyethylene oxide from aqueous acid acetic solution. J Appl Polym Sci 125:1910-1921

43. Ziabari M, Mottaghitalab V, Haghi AK (2010) A new approach for optimization of electrospun nanofiber formation process. Korean J Chem Eng 27:340-354

44. Manandhar S, Vidhate S, Souza ND (2009) Water soluble levan polysaccharide biopolymer electrospun fibers. Carbohydr Polym 78:794-798

45. Chowdhury M, Stylios G (2010) Effect of experimental parameters on the morphology of electrospun nylon 6 fibres. Int J Basic Appl Sci 10:70-78

46. Moreno-Cortez IE, Romero-García J, González-González V, García-Gutierrez DI, Garza-Navarro MA, Cruz-Silva R (2015) Encapsulation and immobilization of papain in electrospun nanofibrous membranes of PVA cross-linked with glutaraldehyde vapor. Mater Sci Eng C 52:306-314

47. Nadem S, Ziyadi H, Hekmati M, Baghali M (2020) Cross-linked poly(vinyl alcohol) nanofibers as drug carrier of clindamycin. press. https://doi.org/10.1007/s00289-019-03027-z

48. Ghasemlou M, Khodaiyan F, Jahanbin K, Garibzahedi SMT, Taheri $S$ (2012) Structural investigation and response surface optimisation for improvement of kefiran production yield from a lowcost culture medium. Food Chem 133:383-389

49. Piermaria J, Bosch A, Pinotti A, Yantorno O, Garcia MA, Abraham AG (2011) Kefiran films plasticized with sugars and polyols: water vapor barrier and mechanical properties in relation to their microstructure analyzed by ATR/FT-IR spectroscopy. Food Hydrocolloid 25:1261-1269

50. Koczkura KM, Mourdikoudis S, Polavarapud L, Skrabalak SE (2015) Poly vinyl pyrrolidone (PVP) in nanoparticle synthesis. Dalton Trans 44:17883-17905

51. Vassovl S, Oras S, Antsov M, Sosnink I, Polyakov B, Shutka A, Krauchanka MYu, Dorogin LM (2018) Adhesion and mechanical properties of PDMS-based materials probed with AFM: a review. Rev Adv Mater Sci 56:62-78

Publisher's Note Springer Nature remains neutral with regard to jurisdictional claims in published maps and institutional affiliations. 